\title{
International Union of Basic and Clinical \\ Pharmacology. Recommendations for GPCR ligand bias
}

\author{
Peter Kolb et al. ${ }^{1}$ and David Gloriam ${ }^{1}$ \\ ${ }^{1}$ Affiliation not available
}

September 10, 2021

\begin{abstract}
G protein-coupled receptors modulate a plethora of physiological processes and mediate the effects of one-third of FDA-approved drugs. Notably, depending on which ligand has activated a particular receptor, it can engage different intracellular transducers. This paradigm of ligand-dependent 'biased signaling' dictates a need to advance beyond the level of receptors to consider the combined ligand-receptor pair in order to understand physiological signaling. Bias signaling also has the potential to improve medicines by reducing adverse effects. However, this is challenged by inconsistent interpretation of results and lack of commonly agreed guidelines. Here, we present recommended terminology and guidelines to conduct, report and quantify bias in a comparable and reproducible fashion. We expect these recommendations will facilitate a common understanding of experiments and findings across basic receptor research and drug discovery, while the area and the analytical methods to measure bias are still evolving, especially in complex cellular, tissue and organismal systems.
\end{abstract}

\section{Author List}

Peter Kolb*1\#, Terry Kenakin ${ }^{2 * \#}$, Stephen P. H. Alexander ${ }^{3}$, Marcel Bermudez ${ }^{4}$, Laura Bohn ${ }^{5}$, Christian S. Breinholt ${ }^{6}$, Michel Bouvier ${ }^{7}$, Fred Ehlert ${ }^{8}$, Stephen J. Hill ${ }^{3}$, Kirill Martemyanov ${ }^{9}$, Rick Neubig ${ }^{10}$, H. Ongun Onaran ${ }^{11}$, Sudarshan Rajagopal ${ }^{12,13}$, Bryan L. Roth ${ }^{2}$, Jana Selent ${ }^{14}$, Arun K. Shukla ${ }^{15}$, Martha E. Sommer ${ }^{16,17}$, and David E. Gloriam ${ }^{6 *}$

${ }^{1}$ Department of Pharmaceutical Chemistry, Philipps-University Marburg, Marburg 35039, Germany

${ }^{2}$ Department of Pharmacology, University of North Carolina School of Medicine, Chapel Hill, North Carolina, USA

${ }^{3}$ School of Life Sciences, University of Nottingham, Nottingham, UK

${ }^{4}$ Institute of Pharmacy, Freie Universitat Berlin, Berlin 14195, Germany

${ }^{5}$ Department of Molecular Medicine, The Scripps Research Institute, Jupiter, FL, USA

${ }^{6}$ Department of Drug Design and Pharmacology, University of Copenhagen, Universitetsparken 2, 2100 Copenhagen, Denmark

${ }^{7}$ Department of Biochemistry and Molecular Medicine, Institute for Research in Immunology and Cancer, Université de Montréal, Québec, Canada

8 Department of Pharmaceutical Sciences, Samueli College of Health Sciences, University of California, Irvine, CA

${ }^{9}$ Department of Neuroscience, The Scripps Research Institute, Jupiter, FL, USA 
${ }^{10}$ Department of Pharmacology and Toxicology, Michigan State University, East Lansing, MI 48824, USA

${ }^{11}$ Ankara University, Faculty of Medicine, Department of Pharmacology, Molecular Biology and Technology Development Unit, Ankara, Turkey

12 Department of Medicine, Duke University Medical Center, Durham, NC 27710, USA.

${ }^{13}$ Department of Biochemistry, Duke University Medical Center, Durham, NC 27710, USA.

14 Department of Experimental and Health Sciences, Pompeu Fabra University, 08003 Barcelona, Spain

15 Department of Biological Sciences and Bioengineering, Indian Institute of Technology, Kanpur, India.

16 Institute of Medical Physics and Biophysics, Charite-Universitatsmedizin Berlin, Berlin 10117, Germany

17 Max Delbruck Center for Molecular Medicine in the Helmholtz Association, Berlin 13125, Germany

\# These authors contributed equally

* Corresponding authors

\section{Introduction}

The 800 human G protein-coupled receptors (GPCRs ) transduce sensory inputs and systemic signals into appropriate cellular responses in numerous physiological processes. They recognize a vast diversity of signals from photons, tastants and odors to ions, neurotransmitters, hormones, and cytokines (Armstrong et al., 2020; Wacker, Stevens \& Roth, 2017). Even though GPCRs represent the primary target of 34\% of FDAapproved drugs, more than 220 non-olfactory GPCRs have disease associations which are as yet untapped in clinical research (Hauser, Attwood, Rask-Andersen, Schioth \& Gloriam, 2017; Sriram \& Insel, 2018). Despite the diversity of ligands and physiological roles of GPCRs, these cell surface receptors share a conserved molecular fold and intracellular transducers. Agonist binding stabilizes active conformations of the receptor, facilitating the binding of one or more cytosolic transducer proteins. These include the heterotrimeric $\mathbf{G}$ proteins consisting of $\alpha, \beta$ and $\gamma$ subunits that dissociate to $\alpha$ and $\beta \gamma$ upon activation by the receptor. G proteins comprise 16 distinct $\alpha$ subunits and are divided into four families based on homology and associated downstream signaling pathways: $G_{\mathrm{s}}\left(\mathrm{G}_{\mathrm{s}}\right.$ and $\left.\mathrm{G}_{\mathrm{olf}}\right), \mathrm{G}_{\mathrm{i} / \mathrm{o}}\left(\mathrm{G}_{\mathrm{i} 1}, \mathrm{G}_{\mathrm{i} 2}, \mathrm{G}_{\mathrm{i} 3}, \mathrm{G}_{\mathrm{o}}, \mathrm{G}_{\mathrm{t} 1}, \mathrm{G}_{\mathrm{t} 2}, \mathrm{G}_{\mathrm{t} 3}\right.$, and $\left.\mathrm{G}_{\mathrm{z}}\right), \mathrm{G}_{\mathrm{q} / 11}$ $\left(\mathrm{G}_{\mathrm{q}}, \mathrm{G}_{11}, \mathrm{G}_{14}\right.$ and $\left.\mathrm{G}_{15}\right)$ and $\mathrm{G}_{12 / 13}\left(\mathrm{G}_{12}\right.$ and $\left.\mathrm{G}_{13}\right)$. Moreover, there are 5 different $\beta$ and $12 \gamma$ subunit types, resulting in a vast number of possible heterotrimeric $G$ protein combinations (Hillenbrand, Schori, Schoppe \& Plückthun, 2015; Masuho, Skamangas, Muntean \& Martemyanov, 2021; Milligan \& Kostenis, 2006; Olsen et al., 2020).

Activated GPCRs are also bound and phosphorylated at multiple Ser and Thr residues by one or more of the seven different GPCR kinases (GRKs ) or effector kinases (e.g. PKA). Receptor phosphorylation by GRKs is a key functional determinant for the binding ofarrestin proteins (4 subtypes), which can 'arrest' signaling by blocking $\mathrm{G}$ protein coupling and facilitating receptor internalization although phosphorylationindependent arrestin interactions have also been described (Eichel et al., 2018). Arrestins are membranelocated scaffold proteins that recruit and/or assemble other proteins that signal (Ahn, Shenoy, Luttrell \& Lefkowitz, 2020). Interestingly, evidence published over the last decade suggests that the pattern and/or distribution of phosphorylated sites on the receptor plays a major role in governing the binding mode and cellular functions of receptor-bound arrestin (Ostermaier, Schertler \& Standfuss, 2014). Ultimately, the functional interplay between G protein, GRK, other kinases, arrestin and other interaction partners at the GPCR shapes the outcome of receptor signaling in space and time (Gutkind \& Kostenis, 2018; Kenakin, 2019). However, the molecular mechanisms underlying these complex and variable interactions remain far from fully understood (Smith et al., 2021; Thomsen et al., 2016). 
'Biased signaling' (also known as agonist-directed trafficking and leading to 'functionally selective' response), is ligand-dependent activation of certain pathways (defined in the next section) over others. The concept is rooted in a natural allosteric behavior of receptors by distinct conformations interacting differently with ligands and cellular transducers at varying stoichiometries and durations. This has allowed endogenous agonists to fine tune their signaling at receptor subtypes throughout evolution. Alternative endogenous agonists directing signaling have been observed for multiple receptors e.g., chemokine (Kohout, Nicholas, Perry, Reinhart, Junger \& Struthers, 2004), opioid (Gomes et al., 2020), PACAP (Spengler et al., 1993), protease-activated (Hollenberg et al., 2014), serotonin (Schmid, Raehal \& Bohn, 2008) and PTH (Dean, Vilardaga, Potts \& Gardella, 2008) receptors.

'Biased signaling' first became evident with numerous reports of aberrations in agonist potency ratios in the mid 1980's following the advent of assays that measured separate effects from G proteins and other cellular transducers (Roth \& Chuang, 1987). Although many of these papers made observations that were compatible with what we now know as bias, relative differences were still difficult to discern from different levels of assay amplification. The general acceptance of biased signaling came with evidence that the order of potency of ligands could be different for different pathways engaged by a single receptor (Spengler et al., 1993) or inversion of the ligand modality (Azzi et al., 2003; Baker, Hall \& Hill, 2003). The first and most frequently studied bias has been that between $\mathrm{G}$ proteins and arrestins, while more recent studies have compared $\mathrm{G}$ protein families and even subtypes belonging to the same $\mathrm{G}$ protein family. An early theory proposed that the bias is caused by the stabilization of different receptor active states by agonists (Kenakin \& Morgan, 1989; Roth \& Chuang, 1987). The allosteric communication between the ligand and G protein has been shown to be reciprocal, as G protein pre-coupling can potentiate agonist binding (De Lean, Stadel \& Lefkowitz, 1980; Lefkowitz, Mullikin \& Caron, 1976; Maguire, Van Arsdale \& Gliman, 1976) and has been explained on the molecular structure level by conformational selection (Galandrin, Oligny-Longpre \& Bouvier, 2007; Kenakin, 1995; Smith, Lefkowitz \& Rajagopal, 2018). An activated receptor state has also been linked to a high affinity binding state for arrestin (Gurevich \& Benovic, 1997). However, it is still unclear what the precise relationship between conformation and signaling is - at least at the level of detail required to predict such outcomes.

Therapeutic exploitation of biased signaling could lead to safer or more efficacious drug therapies. Several studies have outlined disease-relevant pathways for future therapeutic targeting (Urban et al., 2007; Whalen, Rajagopal \& Lefkowitz, 2011) or retrospective cross-screening yielding biased ligands predicted to yield potentially useful phenotypes in therapy (Che, Dwivedi-Agnihotri, Shukla \& Roth, 2021; Galandrin, Oligny-Longpre \& Bouvier, 2007; Kenakin, 2019; Urban et al., 2007; Whalen, Rajagopal \& Lefkowitz, 2011). Biased signaling is presently a very active area for pharmacological research, as it might provide a means to elicit signaling profiles differing from the ones caused by natural hormones and neurotransmitters, thus imparting different qualities of efficacy (mixtures of cellular signaling) to therapeutic systems (Che, DwivediAgnihotri, Shukla \& Roth, 2021; Kenakin, 2021; Urban et al., 2007).

However, the advance of the field is currently hampered by confusing terminology and inconsistent interpretations of results due to a lack of commonly agreed guidelines for reporting bias and the underlying experiments e.g., what has really been measured. Here, we provide recommendations for the terminology to use or avoid and the minimum requirements to conclude, report and quantify bias in a reproducible fashion. The recommendations are supported by the authoritative organization for pharmacological nomenclature, the International Union of Basic and Clinical Pharmacology (https://iuphar.org), and the COST Action CA18133 ERNEST (European Research NEtwork on Signal Transduction) (Sommer et al., 2020). These are not recommendations for how to perform experiments, but to adopt a common terminology facilitating consistent reporting, joint understanding of what has been done and what were the results, and more comparable research data. A clearer understanding of biased signaling may also improve the challenging translation of in vitro findings to disease-relevant in vivo models. 


\section{Pathway definition and modulation}

A GPCR pathway is here defined by a transducer protein, or family thereof, binding intracellularly to the receptor and eliciting a distinct cellular downstream signaling cascade, trafficking or internalization. Based on present knowledge, this includes the four $G$ protein families - i.e., the $G_{s}, G_{i / o}, G_{q / 11}, G_{12 / 13}$ pathways. It also includes the arrestin and GPCR kinase (GRK) families which are recruited to and bind activated GPCRs, even when $G$ proteins are pharmacologically inhibited or when $G_{\alpha}$ proteins are partially or entirely genetically ablated (Grundmann et al., 2018; Hunton et al., 2005; Sauliere et al., 2012; Wehbi, Stevenson, Feinstein, Calero, Romero \& Vilardaga, 2013). For example, GRK4-6 functions do not appear to require either $\mathrm{G}$ proteins or arrestins, as they are not recruited by $\mathrm{G}_{\beta \gamma}$ but anchored to the plasma membrane via polybasic domains and lipid modification (Komolov \& Benovic, 2018). Importantly, functionally relevant bias can also occur across different members of the same protein family and pathway. G proteins belonging to the same family may differ in their functional outcome due to unique binding kinetics, cellular expression levels, and engagement of different downstream effectors (Anderson et al., 2020; Avet et al., 2020; Ho \& Wong, 2001; Jiang \& Bajpayee, 2009; Olsen et al., 2020).

In addition, there are proteins that are modulators of receptors, transducers and effectors and can influence signaling indirectly. For example, receptor activity-modulating proteins (RAMPs) bind to receptors and can alter G protein and/or arrestin binding (Hay \& Pioszak, 2016). In the case of the calcitonin and calcitonin receptor-like receptor, different receptor-RAMP complexes produce distinct pharmacological responses and are therefore considered as separate receptor subtypes: one calcitonin, two adrenomedullin and three amylin receptors (Hay, Garelja, Poyner \& Walker, 2018). Similarly, the cannabinoid CB1 receptor can bind to Cannabinoid Receptor Interacting Protein 1a (CRIP1a) yielding distinct pharmacology (Oliver, Hughes, Puckett, Chen, Lowther \& Howlett, 2020). GPCRs are also substrates for second messenger-activated kinases such as the cAMP-dependent kinase (PKA), protein kinase C (PKC) and the Casein Kinase (CK) with each producing different effects on receptor signaling and trafficking (Bouvier, Leeb-Lundberg, Benovic, Caron \& Lefkowitz, 1987; Hausdorff, Bouvier, O’Dowd, Irons, Caron \& Lefkowitz, 1989; Tobin, Totty, Sterlin \& Nahorski, 1997). It should be noted that, similarly to second-messenger-driven kinases, GRK can also catalyze the phosphorylation of many non-receptor substrates (Gurevich, Tesmer, Mushegian \& Gurevich, 2012). Additionally, numerous downstream intracellular effectors modulate pathway responses as scaffolding proteins e.g., kinases, PDZ proteins) (Bockaert, Fagni, Dumuis \& Marin, 2004; Kenakin, 2019; Maurice, Guillaume, Benleulmi-Chaachoua, Daulat, Kamal \& Jockers, 2011). The regulator of G protein signaling (RGS) proteins selectively modulate $G$ protein subtypes and differentially alter $G$ protein signal strength (Hollinger \& Hepler, 2002; Neubig \& Siderovski, 2002). Furthermore, GRK2 and GRK3 have a regulator of G protein signaling (RGS) homology domain $(\mathrm{RH})$ binding to $\mathrm{G}_{\mathrm{q} / 11}$ to inhibit signaling, and a $\mathrm{PH}$ domain that can bind to $\mathrm{G}_{\beta \gamma}$ to inhibit its signaling while inducing recruitment of GRK to the receptors (Carman et al., 1999; DebBurman, Ptasienski, Benovic \& Hosey, 1996; Ribas et al., 2007). Therefore, it is clear that multiple proteins can influence the ability of a receptor to interact with a transducer.

\section{Terminology summary}

Transducer: For the purpose of defining biased signaling initiated by the GPCRs, transducers are defined as proteins that bind directly to an activated receptor to initiate downstream signaling events. This includes $\mathrm{G}$ proteins, GRKs and arrestins. Some also use 'primary' effector to denote a transducer, although this word can be confusing for these protein families as they typically are engaged consecutively in a signaling cascade (although all bind to the receptor).

Effector: Downstream protein that is a node of the pathway/signaling cascade, i.e., following the transducer. Some also use 'secondary' transducer to denote an effector.

Modulator: Proteins or molecules that interact with the receptor, transducer or effectors to modify the signaling response without mediating it. Examples include RAMPs, GEFs, GAPs, RGSs, NO, cholesterol, other lipids etc.

Second messenger: Small molecules or ions directly controlled by the effectors. Changes in second messenger 
homeostasis mediate cellular responses and can serve as a quantifiable measurement of GPCR activation. Examples include cAMP, calcium, etc.

Pathway: A pathway is named after a transducer protein, or family thereof, that binds to GPCRs and elicits a distinct downstream signaling cascade or cellular response profile. This includes $G$ proteins and their families - i.e., the $\mathrm{G}_{\mathrm{s}}, \mathrm{G}_{\mathrm{i} / \mathrm{o}}, \mathrm{G}_{\mathrm{q} / 11}$, and $\mathrm{G}_{12 / 13}$. It also includes the arrestin and GPCR kinase (GRK) families, which can be recruited to activated GPCRs either dependent or independent of functionally active $\mathrm{G}$ protein heterotrimers.

\section{Ligand bias definition and distinction from receptor and system bias}

This paper focuses on 'ligand-dependent bias' i.e., cases where a receptor's signaling pathway engagement changes as a function of the addition of a given ligand. Quantification of bias typically compares only two transducer pathways at a time and includes the pathway with the strongest signaling. An exhaustive quantitative comparison of all pathways would therefore be constituted by a profile of pairwise comparisons. Quantified bias measures the change in transducer-pathway preference relative to a reference ligand (Table 1) and is therefore a comparison of both pathways and ligands (like a quantitative rank order). In contrast, "nonquantitative bias' (previously termed 'perfect bias' or 'full bias') entails a single ligand's selective signaling through one pathway while the other pathway(s) display no detectable signaling or signaling with another modality (see section "Special recommendation for agonism versus antagonism...").

All ligand-independent mechanisms that may result in functional selectivity are covered by the term "system bias" . Functional selectivity due to system bias is independent from the specific identity of the ligand (i.e. applies equally to all ligands of the same modality), but depends on the properties of the system (i.e. experimental setup, cell type, tissue, receptor reserve etc.). System differences span e.g., constitutive selectivity of receptors for different transducers, spatiotemporal expression levels of signaling proteins (including receptor, transducers, effectors and other members of the signaling pathways), presence or absence of proteins acting on the receptor as allosteric modulators (like RAMPs (Hay \& Pioszak, 2016) or other modulators like kinases (Strachan, Sciaky, Cronan, Kroeze \& Roth, 2010), and finally, presence of intra- or inter-pathway feedbacks are all determinants of system bias. The impact of signaling efficiency of different pathways, on the manifestation of full or partial agonism with agonists of different efficacy is another example of system bias.

In general, 'functional selectivity' is a combination of ligand and system bias. Physiologically, this is exemplified by an endogenous agonist regulating alternative physiological functions in different cells/tissues often differentially expressing signaling components. Some GPCRs lack the inherent capability to elicit G protein coupling while exhibiting robust arrestin interaction (Rajagopal et al., 2010; Shubhi Pandey, 2021). This gives all ligands functional selectivity towards arrestin responses through system bias rather than ligand bias. In drug discovery, this provides an opportunity to elicit predominantly one of several physiological effects that a given receptor can mediate by designing drugs that are transducer- or pathway-selective (i.e. adjusting ligand bias on the background of system bias in the tissues of interest) (Figure 1).

Experimental studies can suffer from so called 'observational bias', which is an artificial bias introduced by the experimental setup. For example, stronger signal amplification in one of two compared pathways when measuring different signaling processes at different levels (Figure 1). Another example would be the use of different cells with different protein expression. Another reason of observation bias is that the readout signals of the studied ligand are below the assay's sensitivity for one pathway, but detectable in the other pathway. This case may be overcome by using more sensitive assays or by increasing expression levels of the involved signaling partners, if feasible. Moreover, the actual signal plateau may be missed if the signal detection tools saturate prematurely or if the measurement time point does not match the ligand binding kinetics. This gives rise to an assay-dependent (nonlinear) amplification in the observed signal(s). Nevertheless, the latter effect is taken care of by bias-quantitation strategies in exactly the same way as the "system-bias" is handled. To test for observational bias, it is recommendable to use an independent 'orthogonal' assay to 
validate each pathway. Furthermore, it is necessary to ensure that at least one assay for each pathway has sufficient sensitivity (preferred) or to increase expression levels of the involved signaling partners (alternative) to overcome sensitivity problems of a particular assay.

Disclaimer: In some cases, it can be difficult to cleanly separate ligand bias and system bias. Furthermore, the use of recombinant and/or overexpressed receptor, transducer or effector proteins may not fully reflect the bias in a native system.

\section{Terminology summary}

Ligand bias: Ligand-dependent preferential activation, by some agonists, of some transducer pathways over others originating from a single receptor subtype relative to a reference ligand (and tested in a given cellular system).

System bias: Bias due to differences in the cellular system, including so called "tissue bias". System bias can be due to differential expression of intracellular transducers or effectors, or of proteins acting on the receptor as an allosteric modulator (e.g. RAMPs; kinases; PDZ proteins).

Functional selectivity: Functional selectivity is the observed response combining ligand- and system-bias (see also (Stallaert, Christopoulos \& Bouvier, 2011)). It covers all instances where a ligand produces disproportional responses, relative to a reference ligand, in different pathways connected to the same receptor.

Observational bias: An artificial bias introduced by the experimental setup. Its final effect on the observed response is quantitatively equivalent to, and thus indistinguishable from, biologically induced system bias. Therefore, ligand bias assessment strategies that are meant to eliminate system effects from observed responses handle observational bias as a "system bias". However, this effect can also be experimentally minimized by measuring signals at similar levels of the compared pathways by using equally sensitive assays, and by ensuring that at least one assay for each pathway has sufficient sensitivity.

Choice of reference ligand determines the meaning of bias, which can be a benchmark or pathway- or physiology-biased ligand/signaling

The GPCR field uses several fundamentally different meanings of biased ligand/signaling and these depend on the choice of reference ligand (Table 1). As these have different meanings, each of them serves a distinct purpose, and substantial portions of the research community will continue to use their favorite type of bias to fulfill the needs of their given studies. Therefore, these recommendations do not prohibit the use of any of these different types of biases, but strive to explain their principles, advantages, and limitations to aid any researcher in designing and interpreting different types of biased signaling studies. A fundamental recommendation of this paper, however, would be that authors are explicit in their descriptions of which version of bias they describe and which reference ligand they used.

Many biased ligand/signaling studies use a particular reference ligand because it is a much-used tool compound (e.g., isoprotenerol/isoprenaline for the $\beta_{2}$-adrenoceptor) or a relevant clinical agent (e.g., an existing drug to be replaced in a new drug discovery project). In this case, the (only) meaning of the observed biased ligand/signaling is that it differs from that of the reference ligands, which in its turn can have a pathwayor physiology-bias. In contrast, 'pathway-biased ligand/signaling' utilizes the reference ligand with the most balanced signaling across pathways, allowing the research objective to identify ligands for or functionally dissect a specific pathway. Finally, 'physiology-biased ligand/signaling' utilizes the principal physiological agonist as the reference ligand and consequently can conclude whether the tested ligands display "natural" or "unnatural" signaling. The three types of biases are described in more detail in the following sections.

\section{Recommendation 1}

1a. Define the bias type: We recommend using the more specific terms 'pathway-biased ligand/signaling' and 'physiology-biased ligand/signaling' rather than just 'biased ligand/signaling'. This is because, although the person who generated the data may have only thought of one preferred meaning of bias, a substantial portion of the community will inevitably understand the meaning of bias differently. 
1b. Include multiple and explain chose of reference ligands: To allow interpretation across bias types and studies, we recommend that experiments include multiple ligands that could serve as reference ligands e.g., a commonly used tool compound and clinical drug, the principal endogenous agonists and/or a pathway-balanced ligand, where available. Furthermore, we recommend to always explain the choice of reference ligands, e.g.: The reference ligand $A$ was chosen, as it A) is the principal physiological agonist, B) has a relatively balanced signaling through pathways P1 and P2 (provide slope coefficient), or C) a clinical or tool compound for which enhanced pathway specificity is desired through the introduction of bias." .

Reason: Bias cannot be reported without the use of a reference ligand, as a presumed bias may otherwise in fact be due to other differences in e.g., the baseline, window and sensitivity of assays ('system bias' and 'observational bias' in Figure 1). System bias affects all ligands equally (including the reference ligand), unless the ligand is labile (e.g. degraded by cellular components (peptidases, lipases, etc.) or is less stable in solution (oxidation, reduction, etc.). Therefore, a pairwise relative comparison of a reference and tested ligand will normally not be influenced by system bias.

Disclaimer: The use of an arbitrary reference ligand does not cancel the effect of system bias on the pairwise relative comparison of pathways in pathway-biased ligand/signaling studies (it does so only for ligands). I.e., a reference ligand cannot support the claim that a ligand has an isolated/preferred signaling via one pathway unless the reference ligand is selected based on balanced signaling.

Case study: Depending upon the reference agonist used, a given tested agonist could be biased towards a given pathway or not. The dependence of bias on the choice of reference agonist is illustrated in the relative activation of $\mathrm{G}$ protein and $\beta$-arrestin pathways by the $x$-opioid receptor with the agonist naphthoyl$\beta$-naltrexamine ( $\beta$-NNTA) (White et al., 2014). Thus, when salvinorin A is chosen as the reference agonist, $\beta$-NNTA is 8.9-fold biased toward G protein signaling, only 2-fold biased toward G protein if salvinorin B is the reference, and 4.3-fold biased toward $\beta$-arrestin recruitment ( 0.23 bias for $\mathrm{G}$ protein) if dynorphin- $\mathrm{A}$ is the reference. Such evidence clearly demonstrates that it is important to report the identity of the reference compound in bias studies and to restrict the conclusions to the comparison made.

\section{Terminology summary}

Reference ligand for bias: The ligand that is, by definition, unbiased. The bias of other tested ligands are quantified relative to this reference.

Reference ligand for Emax: If the reference ligand for bias does not produce a full receptor response, a separate reference ligand for Emax can be used to exploit the full window of response. For the $\mathrm{G}_{\mathrm{s}}$ pathway, some studies use forskolin, which activates adenylate cyclase directly, rather than a reference ligand to determine the maximal response. Both the reference compound for bias and the ligand tested for bias will have their Emax values assigned relative to the reference ligand(s) for Emax for each pathway.

\section{Biased ligands/signaling (using any reference ligand)}

When using any ligand (e.g. a tool compound or clinically relevant ligand), the statement that a tested ligand is biased can only be made relative to the reference ligand (which itself can have any bias).

Recommendation 2: Our recommendation here is to report clearly the identity of the reference compound and to restrict the conclusions to the comparison made. To facilitate cross-study comparison, it is also recommended to consider if a reference ligand can be chosen that has been used repeatedly for the given receptor and pathways before. Commonly used reference ligands are available in the receptor pages in the Guide to Pharmacology database (Armstrong et al., 2020).

Caveat: When the reference ligand is not chosen based on its signaling bias and is not the principal endogenous agonist, the results cannot be used to determine pathway- or physiology-bias (see Table 1 and the two next sections).

Terminology summary 
Biased ligand/signaling: In the broad context of an arbitrary reference ligand, this term solely denotes a difference relative to the reference ligand, which can in turn display any signaling. Hence, this is a normalized quantity, analogous to fold potency, percent efficacy or rank order relation. This term is receptor- and systemdependent and can only be used after an explicit prior definition separating receptor and system bias: e.g., "ligand L displays [recruitment/signaling/..] bias towards pathway P1 over pathway P2 relative to reference ligand A at receptor R in cell line C" (see section Unambiguous description of ligand bias - experiment information).

Unbiased ligand: A ligand that stimulates pathways in a manner indistinguishable from the reference ligand.

\section{Pathway-biased ligands/signaling (using a pathway-balanced reference ligand)}

When using a pathway-balanced reference ligand (typically a surrogate but could be an endogenous ligand) the statement that a tested ligand is biased carries the meaning that it preferentially activates one pathway over the other (Table 1).

Recommendation 3: Our recommendation here concerns which approaches to use to select a reference ligand which is balanced in its signaling (a definition limited to the given investigated systems and assays, see below). In an ideal case, the reference ligand would have identical concentration-response curves in the compared pathways. A way to quantify the similarity of pathway responses is to make a bias plot of an equimolar comparison of induced activities (Figure 2). The most balanced (least biased) ligand is then defined as the one with a slope closest to 1 .

A database of expert-curated pathway-balanced reference ligands will soon be available in GPCRdb, and researchers can deposit their suggested reference ligands via a standardized Excel file detailing information about the pathways and assays to provide context-specific suggested reference ligands (download link).

\section{Disclaimers}

Lacking reference ligand: A sufficiently balanced ligand may not yet exist for all investigated receptors and pathways. In these cases, bias can still be measured but should not be considered an assessment of pathway-bias but rather a benchmark relative to a given, general reference ligand (see preceding section). When no balanced ligand is available, one can show a bias plot for each tested ligand.

Context specific bias: Many researchers argue, rightly so, that a ligand referred to as balanced will not be balanced in another system or assay. Therefore, any claim of a ligand being balanced and tested ligands exhibiting pathway-bias is always system specific (which is also true for all biased ligand/signaling studies).

\section{Terminology summary}

Balanced ligand/signaling: Near equal signaling through compared pathways. In the context of pathwaybiased ligands/signaling, the reference ligand is a balanced ligand.

Pathway-biased ligand/signaling: Ligand/signaling that is biased relative to a balanced reference ligand and therefore bears the meaning that signaling is preferentially through a given pathway.

\section{Physiology-biased ligands/signaling (using a principal endogenous agonist refer- ence)}

When using the principal endogenous agonist as a reference ligand, the statement that a tested ligand is biased carries the meaning that its transducer pathway engagement differs from the physiological one (Table 1 ). Whether this entails a response through a single isolated pathway or not will therefore depend on the extent to which the physiological ligand engages different transducer pathways. 
Recommendation 4: A study seeking to explore to what extent a tested ligand differs from the natural signaling of a receptor system should use the principal endogenous agonist as reference ligand. Furthermore, we recommend that all bias studies include the principal endogenous agonist (unless it has too low efficacy in a pathway), as this facilitates subsequent comparison across studies and laboratories. The principal endogenous agonist is defined as the one which is most active and available in the highest concentration in the same tissues as the receptor. The principal and secondary endogenous agonists of GPCRs are curated by experts coordinated by the Nomenclature and Standards Committee of the International Union of Basic and Clinical Pharmacology (IUPHAR, https://www.guidetopharmacology.org/nciuphar.jsp) and available in the BPS/IUPHAR Guide to Pharmacology database (Armstrong et al., 2020). In cases where it is not clear which endogenous agonist represents the principal version, we recommend using the endogenous agonist with the highest potency (as efficacy is not annotated in this database) or efficacy in the given assay and system (if tested). As a note, a secondary endogenous agonist can be biased relative to the principal endogenous agonist.

Reason: By using an endogenous agonist as reference, the study better approximates how the ligand tested for bias can alter a receptor's presumed physiological signal. This is valuable if it is, for example desired to steer signaling away from a pathway that is associated with an unwanted response, such as an adverse drug effect, or wanting to design a probe to determine a specific pathway's effect in the first place.

Disclaimer: Physiology-bias cannot be determined in cases when no endogenous ligand is known (an 'orphan' receptor). Furthermore, it cannot be quantified when the endogenous agonist(s) do not have sufficient efficacy in the studied pathways to ensure robust detection.

\section{Terminology summary}

G protein selectivity (NOT 'natural bias') : The repertoire of G proteins that a receptor can engage. The term 'natural bias' should not be used as it is an oxymoron i.e., is self-contradictory.

Physiology-biased ligand/signaling: Ligand/signaling that is biased relative to a receptor's principal endogenous agonist, and therefore bears the meaning that signaling is non-physiological/unnatural.

\section{Unambiguous description of ligand bias - experimental evidence}

Recommendation 5: Our foremost recommendation is to describe ligand bias unambiguously by including the major information in an initial statement, e.g.: "ligand L displays [recruitment/signaling...] bias towards pathway P1 at time point TP1 over pathway P2 at time point TP2 and relative to reference ligand $A$ at receptor $R$ in cell line $C$ " .

Of course, reference ligand A must be measured under identical conditions as ligand L at each pathway. Like any definition, this should be mentioned at the first mention of the biased ligand - also in articles that reference data from another, original article. Additionally, we recommend that authors tabulate experimental details critical to the unambiguous description of ligand bias (a template is provided in Table 2). The suggested tabulated experimental details extend the above single-sentence statement with information about temperatures, signal detection techniques and the measured molecules. The time points refer to data collection times (see section Kinetics and choosing measurement time points).

Reason: All the above information is necessary to interpret ligand bias correctly and to separate it from system bias (Figure 1). Hence, the mention of a 'biased' or 'unbiased' ligand as short terms are only meaningful after the prior definition of this information. The recommended statement and tables will facilitate meaningful comparisons of ligands and avoid different definitions leading to different conclusions from different researchers. The more consistent and comprehensive information provided in this statement will also greatly improve clarity and transparency while easing the annotation of biased ligands for review articles or databases. 
Disclaimer: It follows from our recommendation 5 that assays that do not use the same reference agonist for bias or the same experimental conditions do not "disprove" biased agonism.

\section{Unambiguous description of ligand bias - quantification models and raw data}

Strategies used to quantify ligand-bias are all based on, and derived from, the principles of classical theory of receptor action (Furchott, 1966; Stephenson, 1956). The common objective of all these methods is to separate ligand-dependent parameters from the system-dependent ones in observed responses. However, there is still different views of how to best quantify bias and strategies for quantification are still being developed/improved. Hence, there are numerous models that could be used as long as pathways are measured with consistent pharmacological parameters and in similar systems and assays with corresponding levels of downstream processes and kinetics (see below sections). Of note, even with the most detailed models it is not possible to directly compare quantitative estimates of bias across different studies.

\section{Recommendation 6}

At the present time, we are unable to recommend a single quantification method due to the lack of consensus in the community, with new or refined methods are still being proposed. Many methods are based on the null principle of equieffective concentrations of agonist producing equal responses first described by (Barlow, Scott \& Stephenson, 1967). Thus, simultaneous comparison of the concentration-response curves of two agonists gives ratios of the efficacy and affinities of the two agonists which form the basis of methods to quantify bias. The two commonly used quantities, i.e. relative-relative $\log \left(\mathrm{E}_{\max } / \mathrm{EC}_{50}\right)$ (Ehlert, 2008) and relative-relative $\log \left(\tau / \mathrm{K}_{\mathrm{A}}\right)$, emanate from this work. These quantities are theoretically justified within the framework of the Black-Leff operational model (Black \& Leff, 1983), a specific implementation of the classical theory, which provides a fitting equation for concentration response curves. The two models first compare the tested ligand relative to the reference ligand in each pathway and then compare across the two pathways. When the slope factors (Hill coefficient) of ligand concentration-response-curves are 1 (Figure 2) the Log(Emax/EC 50 ) values are identical to $\log \left(\tau / \mathrm{K}_{\mathrm{A}}\right)$ values. However, when they are not, the $\log \left(\operatorname{Emax} / \mathrm{EC}_{50}\right)$ values have the disadvantage that their bias factors are less comparable, as they are influenced by different receptor expression in the pathway experiments whereas the $\log \left(\tau / \mathrm{K}_{\mathrm{A}}\right)$ values take into account receptor density and coupling within a system.

We may refer readers to (Kenakin, 2019) for a comprehensive review of available implementations of bias quantification and Onaran \& Costa, 2021 (Onaran \& Costa, 2021) for a critical review of the detailed principles, on which specific implementations are based.

Disclaimer: Quantification of bias using different methods, even those based on the same theory, can in some cases lead to different conclusions on the biased/unbiased nature of a ligand (and system) (Onaran et al., 2017; Rajagopal et al., 2011) or to a different relative bias rank order of a set of tested ligands. Hence, results will be more definitive when bias is quantified using multiple models. Furthermore, none of the available strategies can provide an absolute bias value of a given ligand at a given receptor. Only bias values relative to a reference ligand are accessible with current quantitation techniques.

Avoid: A large degree of caution is advisable for describing ligands with only weak bias or absolute efficacy, as these compounds are more likely to produce system-dependent biased effects (see section Special recommendation for low efficacy agonists). Such agonists are therefore more likely to be spuriously identified as biased, as both methods outlined above rely on best-fit parameters. Weak partial agonists will result in relatively poor fits (but still with excellent $\mathrm{R}^{2}$ ) with $\mathrm{E}_{\max } / \mathrm{EC}_{50}$ or $\tau / \mathrm{K}_{\mathrm{A}}$ values that grossly underestimate the errors of the derived bias factors. One can use a bias plot to confirm non-quantitatively that bias exists between two compounds, but one should never rely on bias factors alone. 


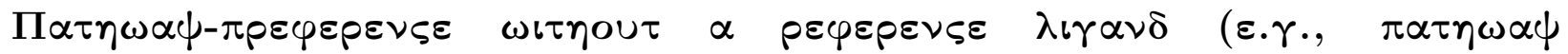 $\Delta \operatorname{\Lambda o\gamma }\left(\mathrm{E}_{\mu \alpha \xi} / \mathrm{E}^{\mathrm{ec}}{ }_{50}\right)$ op $\Delta \operatorname{\Lambda o\gamma }\left(\tau / \mathrm{K}_{\mathrm{A}}{ }^{\prime}\right.$}

Recommendation 7: Investigation of a ligand's differential activity across pathways (e.g. pathway $\Delta \log \left(\mathrm{E}_{\max } / \mathrm{EC}_{50}\right)$ or $\Delta \log \left(\tau / \mathrm{K}_{\mathrm{A}}\right)$ values), but not relative to a reference ligand, is herein not considered a biased ligand/signaling study but instead defined as 'pathway-preference'. As no reference ligand is used, the comparison must be made ideally using the same or otherwise near-identical systems and assays.

\section{Disclaimers}

Assay/system dependence: If the system or assays change, the same ligand and receptor may display a very different pathway-preference. However, the same may actually be true even when using a reference ligand, as that does not equate any imbalance in pathways, but merely move the baseline. Imbalance in pathways is instead predominantly determined by the choice of systems and assays, which should be as similar as possible.

Fold potency: Fold potency comparisons without the inclusion of efficacy are merely to be seen as a prediction of potential pathway-preference or bias, as in case the efficacies were known, the real relationships may be very different.

\section{Terminology summary}

Pathway-preference: A ligand's differential activity across pathways (e.g. pathway $\Delta \log \left(\mathrm{Emax} / \mathrm{EC}_{50}\right)$ or $\Delta \log \left(E \max / \mathrm{EC}_{50}\right)$ values $)$, not comparing to a reference ligand. As no reference ligand is used, the comparison must be made ideally using the same or otherwise near-identical systems and assays.

\section{Report underlying quantitative data of bias factors}

Recommendation 8: We recommend authors to tabulate the underlying quantitative values of the pharmacological parameters used to calculate a bias factor (templates are provided in Tables 3-4). Reporting these values will improve clarity, increase transparency and future-proof cross-study comparisons. It also allows databases to calculate and present multiple models of bias or to change the choice of reference ligand to facilitate comparison across studies. Furthermore, we recommend always reporting slope factors of the

concentration-response curves. This information is critical especially when $\Delta \Delta \log \left(\operatorname{Emax} / \mathrm{EC}_{50}\right)$ is used to assess bias, as slope factors deviating from 1 indicate the extent to which system bias (rather than ligand bias) contributes to the calculated bias factors.

\section{Bias measured at the level of GPCR-binding transducers}

\section{Recommendation 9}

9a. We recommend that a larger set of known and predicted biased ligands are characterized using recent assays opening for consistent profiling across broad panels of $\mathrm{G}$ proteins and arrestins (also with GRKs) (Avet et al., 2020; Olsen et al., 2020).

Reason: When the signal is measured at the transducer (a G protein, GRK or arrestin), there is no downstream signal amplification (although different systems can express receptors and transducers differentially). The upside of this is that signals are more comparable across pathways.

Disclaimer: Amplified signals may be more relevant than those of primary transducers to explain a tissuelevel or systemic response. Also, the transducer signal may differ from the true amplified signal (such as second messenger, Figure 3B).

9b. If possible, we recommend to test all or as many as possible transducers for each investigated transducer family. If not all transducer subtypes within a given transducer family (e.g. $\mathrm{G}_{\mathrm{q}}, \mathrm{G}_{11}, \mathrm{G}_{14}$ and $\mathrm{G}_{15}$ in the $\mathrm{G}_{\mathrm{q} / 11}$ family) can be tested, we recommend testing the transducer subtype with the highest activation or 
recruitment and presence in the given studied cell type. Data to support such selection have, for example been produced for many GPCRs in consistent profiling across broad panels of G proteins and arrestins (Avet et al., 2020; Inoue et al., 2019; Olsen et al., 2020) and integrated in GproteinDb (https://gproteindb.org) and ArrestinDb (https://arrestindb.org), respectively.

Reason: $G$ proteins belonging to the same family may differ in their functional outcome due to unique binding kinetics, cellular expression levels, and engagement of different downstream effectors (Anderson et al., 2020; Avet et al., 2020; Ho \& Wong, 2001; Jiang \& Bajpayee, 2009; Olsen et al., 2020). Similarly, differential recruitment of the two isoforms of $\beta$-arrestin ( $\beta$ arr1 and 2) can translate into distinct functional outcomes with respect to regulatory and signaling paradigms (Ghosh et al., 2019; Srivastava, Gupta, Gupta \& Shukla, 2015). If two pathways are compared based on transducer subtypes that represent the maximum and a low activation, respectively, compared to all members of their respective transducer family, this skews the bias comparison of the transducer families (not the specific subtypes). Differential activation or recruitment of transducer family members has been shown both for G protein families (Avet et al., 2020; Inoue et al., 2019; Olsen et al., 2020) and the arrestin family (Avet et al., 2020; Srivastava, Gupta, Gupta \& Shukla, 2015).

Bias measured downstream - minimize differential signal amplification and report measured molecules and processes

Whereas bias is often grouped onto pathways represented by the primary receptor-binding transducers $(\mathrm{G}$ proteins, GRKs and arrestins), most studies instead measure downstream effector proteins or second messenger molecules which can have a differential signal amplification (also in the same system). Hence, bias values may differ when comparing downstream molecules instead of primary transducers in the same pathways (Figure 3B).

\section{Recommendations 10}

10a. Measure at similar pathway levels: We recommend measuring bias at the same or similar depth of compared pathways. Where the readout for one pathway is measured further downstream than for another, one should take special care by noting potential amplification effects.

10b. Report measured molecules: To provide clarity on what has been measured, we recommend that the pathways are not only referred to by the GPCR-binding transducer, but additionally by the downstream molecule or molecule pair that was measured to generate the signals in the experiments.

10c. Report measured processes: As the same molecule can be involved in related but distinct steps of the signaling, we also recommend reporting the measured process. An example of separate processes involving the same (hetero)protein is $\mathrm{G}$ protein receptor-binding versus subunit dissociation. A non-exhaustive list of terms to distinguish such signaling processes is visualized in Figure 3A and tabulated in Table 5 along with example assay principles. It is not sufficient to describe an assay or experiment by the detection method, e.g., a 'BRET assay', as the same detection technique can be used to measure different molecules and processes, such as GPCR-G protein binding/coupling and $\mathrm{G}_{\alpha}-\mathrm{G}_{\beta \gamma}$ dissociation. Furthermore, any receptor, transducer and effector modifications must be explicitly defined (i.e. tags, chimeras, etc.).

10d. Consider pathway convergence: Several pathways intercept each other or converge, meaning that one measured molecule can have been activated and inhibited through multiple primary transducers simultaneously. For example, extracellular signal-regulated kinase (ERK) proteins can be activated by all four G protein families (Jain, Watson, Vasudevan \& Saini, 2018) and this process is shaped in space and time by arrestins and GRKs (Eichel, Jullie \& von Zastrow, 2016; Gutkind \& Kostenis, 2018; Wehbi, Stevenson, Feinstein, Calero, Romero \& Vilardaga, 2013). For this reason, studies reporting bias at downstream effectors or second messengers need to carefully consider whether multiple pathways could have contributed to the effect and, if so, interpret findings in light of their relative strength for the given receptor and ligand. For example, calcium, PKC or DAG measurements should not be equated exclusively with $\mathrm{G}_{\mathrm{q}}$ activation. Indeed, different receptor transducers, including $G_{\beta \gamma}$ released from $G_{\alpha \iota}$ can also lead to the generation of 
these second messengers and activation of this kinase (Dorn, Oswald, McCluskey, Kuhel \& Liggett, 1997). Therefore, the specific type of measurement should be provided. When pathways are truly inseparable and their contributions cannot be dissected using upstream assays, the bias may be considered a type of 'effector bias' (instead of pathway-bias) accounting for the net pathway contributions.

\section{Kinetics and choosing measurement time points}

Recommendation 11: The time points refer to data collection times, which should be carefully selected based on kinetic parameters and residence time, where known. For instance, comparing non-equilibrium readings with equilibrium reading due to different binding kinetics or type of biological responses (ion flux vs. reporter gene) can be a major confounding factor (Klein Herenbrink et al., 2016). When possible, complete time courses are preferred and could be quantified by onset kinetics, e.g. time constant tau $(\tau)$ or time to reach half maximal response amplitude (Hoare, Pierre, Moya \& Larson, 2018). When a single time point is chosen, it should be controlled to ensure that it measures maximum effect (peak), or otherwise the physiologically most relevant time point. This would often be the same across pathways but could differ if different biological processes are measured that occur at different time scales. In all cases, the reasons for the time selected should be reported. See also (Lane, May, Parton, Sexton \& Christopoulos, 2017).

\section{Terminology summary}

Temporal effect: The effect on a measured response due to the choice of time point at which a response is recorded. Apparent biases can occur simply because the kinetics of the response is different between two pathways for two different ligands. These time effects include effects of the binding kinetics $\left(\mathrm{k}_{\mathrm{on}}\right.$ and $\left.\mathrm{k}_{\mathrm{off}}\right)$, time course of the biological response measured and time domain of the assay itself (e.g. reporter gene vs ion flux).

\section{Spatial/Location Bias: Signaling with different efficacies from different cellular compartments}

GPCRs have been shown to signal from a wide range of cellular compartments other than the plasma membrane, including endosomes, the Golgi and the nucleus (Crilly \& Puthenveedu, 2021; Jong, Harmon \& O'Malley, 2019). This signaling can be from different transducers, such as $\beta$-arrestins (Luttrell et al., 2001), G $\alpha$ subunits (Feinstein et al., 2011; Irannejad et al., 2017), and G $\beta \gamma$ subunits (Masuho, Skamangas, Muntean \& Martemyanov, 2021). With this has come the realization that signaling from the same transducer from different compartments can have distinct outcomes; for example, cAMP evolution from endosomes but not the plasma membrane promotes gene transcription (Tsvetanova \& von Zastrow, 2014). This phenomenon of GPCR signaling through the same transducer in different locations producing distinct signaling responses has been referred to as spatial or location bias.

Recommendation 12: For assays of signaling from different cellular compartments, the specific biosensors and tags used for monitoring compartment-specific signaling should be described. The specific cell types used in assays should also be mentioned, as some cell types lack transporters, such as OCT3/SLC22A3, required for the trafficking of hydrophilic small-molecule ligands that cannot cross the plasma membrane (Irannejad et al., 2017). Ligands that have altered characteristics, e.g., permeability, through chemical modification should be fully described with respect to their signaling from different compartments (Jensen et al., 2017).

\section{Terminology summary}

Spatial/Location bias: The observation of biased GPCR signaling through the same transducer in different locations that results in distinct signaling responses. This GPCR signal may originate from different compartments or may be from the same compartment but then result in the trafficking of transducers to different compartments (Masuho, Skamangas, Muntean \& Martemyanov, 2021). 


\section{Special recommendation for low efficacy agonists}

Problem: A compound may have apparent bias (yet show strong functional selectivity) arising from low efficacy in one pathway, leading to the absence of response in that pathway. This can erroneously be interpreted to mean that this response will also never appear in other (more sensitive) tissues, which may or may not be the case. Calculating bias factors with such data is not helpful (due to the large errors associated with essentially zero signaling in one assay).

Recommendation 13: To avoid misleading conclusions based on low efficacy, we recommend investigating the rank order i.e., normalizing within the transducers for each ligand without referencing to other ligands. Only a transducer/pathway rank order change would constitute biased signaling. For example, if ligands A and $B$ share rank order $G_{s}>G_{q}>>$ arrestin they are not biased relative to each other. However, if a third ligand, $C$ differs e.g. arrestin $>G_{q}>>G_{s}$, it is biased relative to A and $B$.

Furthermore, bias quantification should be considered together with the quantified strength of intrinsic efficacy of ligands in the particular relevant signaling pathways. This is because organ sensitivity and relative intrinsic efficacy differences have a large influence on a low-efficacy (for some pathways) ligand which may appear to be very functionally selective in some organs. This may lead to the surprising appearance of a signal in a more sensitive organ.

Disclaimer: Lack of response in a low efficacy pathway does not preclude the antagonism of the natural agonist for that pathway. Thus, a physiological bias can be produced by a synthetic ligand's combined own response (e.g. full agonism in pathway 1) and blockade of the endogenous response (e.g. partial agonist in pathway 2).

\section{Terminology summary}

Reference agonist(s) for Emax: When no single reference ligand with full efficacy across all compared pathways is available, different reference ligands can be used to define Emax in each pathway. The reference ligand and all tested ligands should have their efficacy compared (e.g. \% or value $0-1$ ) to the reference agonist(s) for Emax.

\section{Special recommendation for biased inverse agonism in compared pathways}

Recommendation 14: When a ligand acts as an inverse agonist in two pathways compared for bias, a bias factor can in theory be calculated in the same way as for agonists. However, the reference ligand would need to be another inverse agonist, i.e., in this case it would be warranted to not use the endogenous ligand, as it typically is an agonist (agouti is a rare example of an endogenous inverse agonist).

Reason: Inverse agonists inhibiting the non-ligand-dependent constitutive activity of a receptor may, just as well as biased agonists do, act differentially on pathways by stabilizing distinct receptor conformations. This is only evident for receptors with constitutive activity in the absence of an agonist. The minimum condition needed to quantify bias would be concentration-response curves in two pathways and this condition can be met for an inverse agonist ligand. For receptors with a high constitutive activity, biased inverse agonism could be valuable to understand fundamental signaling and to exploit this therapeutically.

Further reading: Specific discussion of the actual methods to quantify bias for inverse agonists are beyond the scope of this paper, as they involve differences in agonist-mediated and constitutively mediated efficacy (Ehlert, Suga \& Griffin, 2011). Specifically, it is known that constitutively active receptors themselves possess an efficacy that can be different from agonist-mediated efficacy; this is manifest in the phenomenon of protean agonism whereby a low efficacy partial agonist demonstrates positive agonism in quiescent systems and inverse agonism in constitutively active systems (Chidiac, Nouet \& Bouvier, 1996; Kenakin, 1997). This is due to the fact that the agonist-mediated active state is of lower efficacy than the constitutively active state. Such phenomena must be considered to ascribe an efficacy to an inverse agonist. 


\section{Special recommendation for bias-inducing allosteric modulators}

Recommendation 15: For bias-inducing allosteric modulators, it is essential to specify which combination of allosteric modulator and orthosteric ligand was used to determine bias of the latter (Slosky, Caron \& Barak, 2021).

Reason: For bias-inducing allosteric modulators, which do not convey agonism on their own, the functional outcome can vary for different orthosteric ligands, in line with the probe dependency of bias. As no concentration-response curves can be measured for such an allosteric ligand on its own, bias cannot be attributed to it individually.

\section{Comparing ligand bias across studies and systems using rank orders}

Recommendation 16: We recommend using ligand rank orders of bias factors (rather than quantitative bias values) for comparisons of ligand bias across studies using different experimental systems. When comparing more than two pathways, the preferentially activated pathway must be identical and the second pathway should be the next-most efficacious, which could differ for two ranked ligands or studies.

Reason: Bias values obtained from different experimental systems are typically not comparable on a quantitative level. For example, a bias value above 2.0 in one system may be below 2.0 for the same pathways when studied in another system differing by e.g., cell line, measured molecules or process (Figure 3). Achieving a more consistent assessment of which ligand is the most biased towards a given pathway is important to identify functionally selective probes that can be used to dissect a distinct effect. This provides information about which pathways should be targeted or avoided in the design of drugs with higher efficacy and fewer side effects.

Disclaimer: The relative ligand bias rank orders may also differ across systems (Figure 3B). However, they are expected to differ less than detailed quantitative values.

\section{Special recommendation for agonism versus antagonism in compared pathways ('non-quantitative bias')}

Recommendation 17: When agonism and no agonism (neutral antagonism or inverse agonism), respectively, are observed in two pathways compared, it is not possibly to quantify bias using the above models. This is because calculation of a quantitated bias factor requires two concentration-response curves with the same modality (agonism or inverse agonism). However, the bias can be described as a non-quantitative term, "non-quantitative bias".

Alternatively, it can be approximated by measuring an affinity to limit bias or describe it in a "bias is larger than" relationship (Kenakin, 2015; Stahl, Ehlert \& Bohn, 2019; Stahl, Zhou, Ehlert \& Bohn, 2015). Specifically, the affinity (determined from functional antagonism) is used to determine receptor occupancy and a very low level of efficacy is assumed to generate a simulated curve (i.e. maximal response of $5 \%$ ) which is then used to calculate bias. This yields the lowest possible bias (it could be greater than this if the efficacy is lower than the assumed one giving $5 \%$ maximal response).

Reason: In this case, there is no need to quantify bias to claim bias. Thus, a non-quantitative statement would be good enough to specify the case.

Disclaimer: Although a very low ligand efficacy cannot be detected in one system, it may be detected in another functional system with higher sensitivity. Hence, the statement should be understood as a practical qualification, in the sense that the efficacy of the ligand is close to zero within the detection limits of the given system. I.e., some partial agonists may appear to be neutral antagonists.

Terminology summary 
Non-quantitative bias: Ligand with efficacy in only one of compared pathways (neutral antagonist or inverse agonist in others). As for all biased ligands, this refers to a particular system and in another more sensitive system, there may be efficacy at several compared pathways allowing the determination of concentrationresponse curves. We discourage the use of the previous terms 'full bias' or 'perfect bias', as they can misleadingly give the impression that the ligand has full efficacy in the preferred pathway. In fact, a ligand with non-quantitative bias may give a weaker activation than other agonists for which bias can be quantified (as they induce agonism in at least two pathways).

\section{Conclusion and outlook}

The scope of adoption of the recommendations presented herein will ultimately depend on their utility across the wide GPCR field, which will benefit from a common, standardized and therefore comparable characterization of ligand bias. This precise characterization will also help individual researchers, as the more comparable and reproducible research data are, the more useful they will be for others, and the fewer surprises encountered because of irreproducible experiments will occur. Furthermore, the unambiguous and structured reporting of bias data will be directly reflected in more relevant databases and literature reviews.

Ligand-dependent biased function is also being investigated for other protein classes e.g., receptor tyrosine kinases (Karl, Paul, Pasquale \& Hristova, 2020), nuclear receptors (Heidari et al., 2019), monoamine transporters (Hasenhuetl, Bhat, Freissmuth \& Sandtner, 2019), Toll-like receptors (unpublished), and cytochrome P450 enzymes (Jensen et al., 2021). Many of the recommendations brought forward in this paper are also applicable to these protein families, which would in time benefit from publication of additional dedicated guidelines.

To unlock the rational targeting of specific desired physiological biases mediated by GPCRs, we must first map individual or combined pathways to their distinct effects. This requires identification of many more biased probes, pharmacological assays, animal models etc. This represents a tremendous challenge, but one with extraordinary potential. The recommendations herein can contribute to this massive endeavor by better description of such probes and effects. We have deliberately left the door open to include additional intracellular transducers, effectors or modulators involved in GPCR signaling and our definitions should therefore be future proof in the sense that they can be applied also to signaling proteins that have yet to be discovered.

\section{Acknowledgements}

We acknowledge Kasper Harpsøe, Mette M. Rosenkilde and Nevin Lambert for comments on this manuscript. D.E.G. received financial support from the Lundbeck Foundation (R313-2019-526) and Novo Nordisk Foundation (NNF18OC0031226). P.K. thanks the German Research Foundation DFG for Heisenberg professorship KO4095/5-1. M.B. (Marcel Bermudez) thanks the German Research Foundation DFG for funding DFG-407626949. M.E.S., D.G., P.K., XX, YY, and ZZ are members of COST Action CA18133 "ERNEST". E.K. was supported by the DFG-funded research unit FOR2372 with the grants KO1582/10-1 and -2.

\section{Author contributions}

Conceptualization, D.E.G., P.K. and T.K.; Writing - Original Draft, D.E.G., P.K. and T.K.; Writing Review \& Editing, all authors, M.E.S.; Visualization, C.B., D.E.G.; Project Administration, D.E.G.; Funding Acquisition, D.E.G., E.K., P.K., M.B.

\section{Conflicts of interest}

M.B. is the president of Domain Therapeutics scientific advisory board. 
Figures and Tables

\section{Functional selectivity}

Combined ligand and system bias

Each bias is relative (tested vs. reference)

\& Origin of bias

$\square$ \& $\square$ Effect of bias

\section{Ligand bias}

Different ligands and receptor conformations
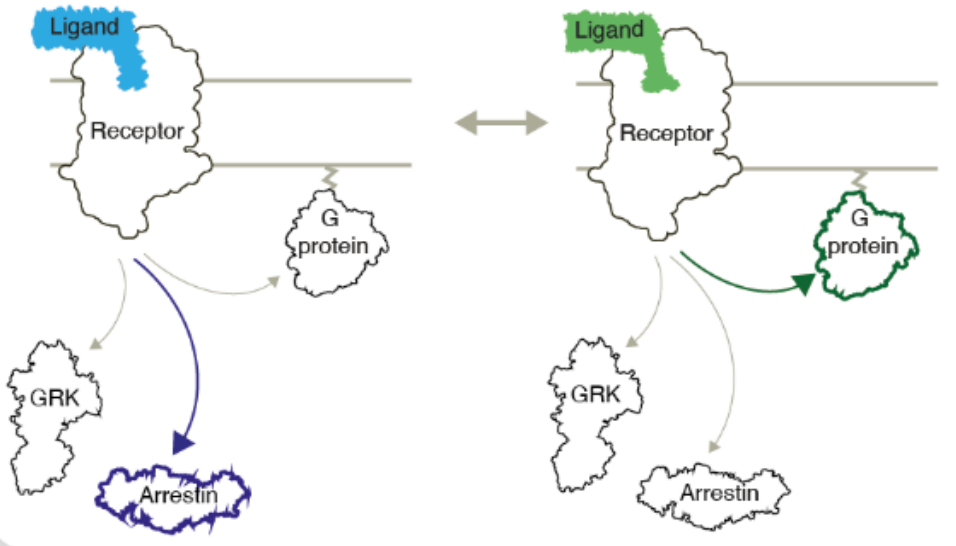

System bias

Different effector concentrations
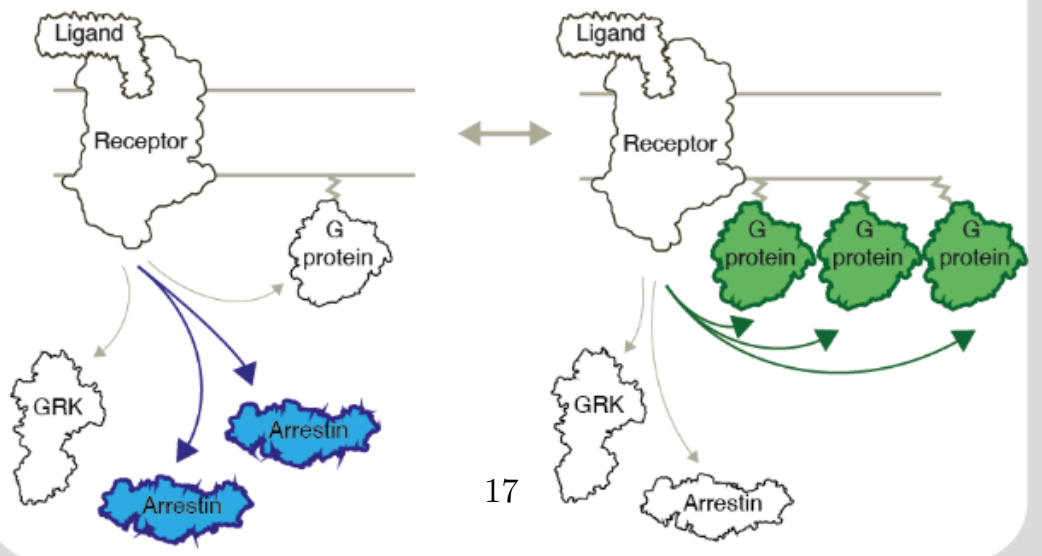
Figure 1. Ligand, system and observational bias.

Ligand and system bias together determine the functional selectivity (see Terminology subsection for definitions). Each type of bias is measured relative to a reference. Observational bias is not of biological origin, but a consequence of assay sensitivity/non-linearity and the parameters chosen in the experimental setup (which may or may not be appropriate for the intended measurements and efficacies of ligands).

\section{Bias Plot}

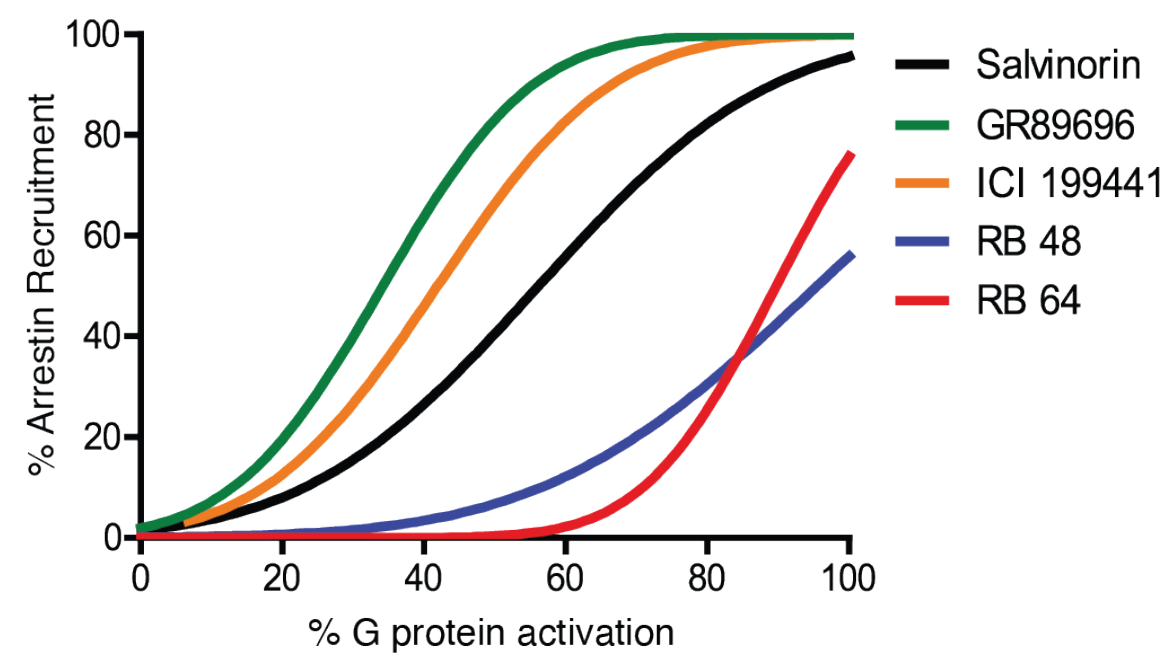

Figure 2. Bias plot of an equimolar comparison of ligand-induced activities in two pathways.

The plot is adapted from (White et al., 2014) in which Salvinorin A was chosen as the reference ligand because it has a slope close to 1 . It also has very similar $\mathrm{pEC}_{50}$ values (5.2 and 5.8) for both the G protein and arrestin pathways and displays full efficacy at both pathways. 

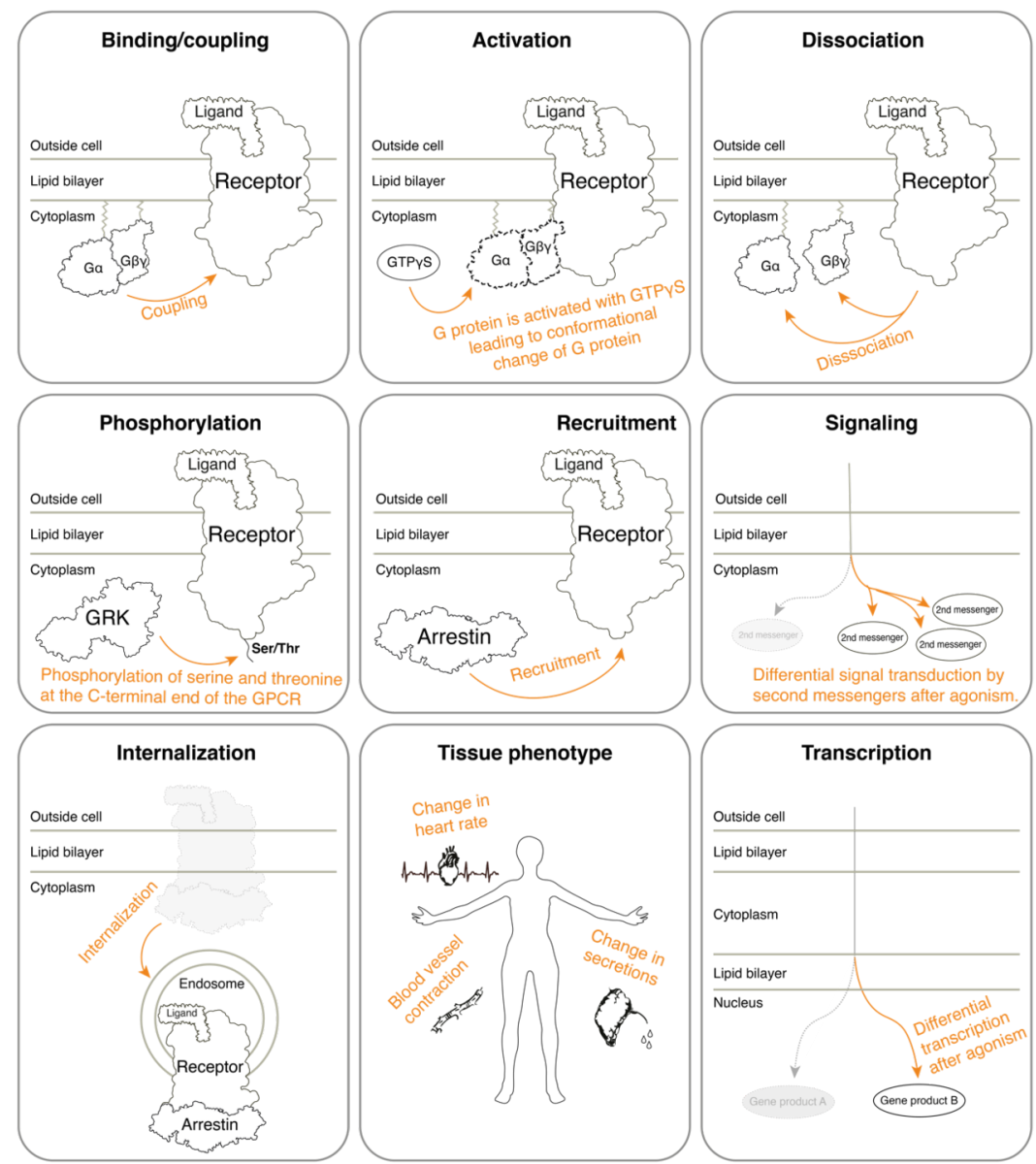

B

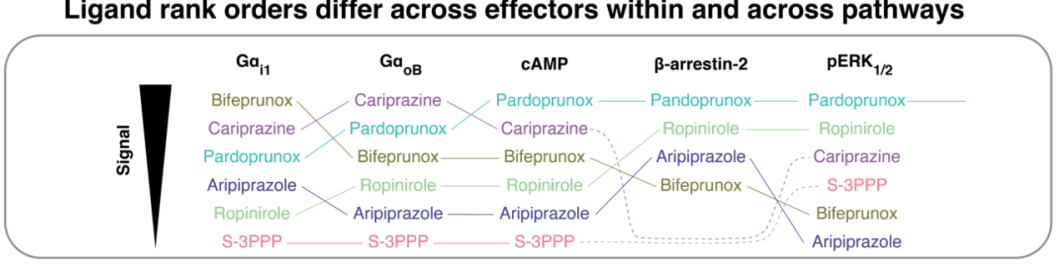

Figure 3. Recommendations to describe the measured pathway process and molecules.

A) Terms to describe the measured pathway process. Also see reviews describing the translation across these levels (Luttrell, Maudsley \& Gesty-Palmer, 2018), assays (Smith, Lefkowitz \& Rajagopal, 2018) and animal models (Bradley \& Tobin, 2016).

B) Data from (Klein Herenbrink et al., 2016) shows the relative bias of dopamine $\mathrm{D}_{2}$ receptor agonists for six pathways (all with dopamine as the reference ligand). The relative order of the biased ligands changes depending on the measured molecules, even across those participating in the same pathway. This emphasizes that bias should be measured at similar pathway depths (as proximal/distal to the receptor), each of which should be defined with respect to the measured molecules.

Table 1 
Types of bias and their meaning by choice of reference ligand. The terms 'pathway-biased ligand/signaling' and 'physiology-biased ligand/signaling' are recommended when researchers wish to attribute a specific function (in addition to just a difference to the reference ligand employed).

\begin{tabular}{|c|c|c|c|}
\hline Type of bias & Reference ligand & $\begin{array}{l}\text { Meaning (what can be } \\
\text { concluded from data) }\end{array}$ & $\begin{array}{l}\text { Disclaimer } \\
\text { (meanings/conclusion } \\
\text { not supported by data) }\end{array}$ \\
\hline $\begin{array}{l}\text { Biased ligand / } \\
\text { signaling }\end{array}$ & $\begin{array}{l}\text { Any ligand e.g., a } \\
\text { candidate drug or tool } \\
\text { compound. The } \\
\text { reference ligand could } \\
\text { be arbitrary, but often } \\
\text { has a particular } \\
\text { relevance as tool or } \\
\text { clinical agent and is } \\
\text { therefore selected to } \\
\text { benchmark other, } \\
\text { tested ligands. }\end{array}$ & $\begin{array}{l}\text { Simultaneous } \\
\text { comparison across } \\
\text { pathways and ligands } \\
\text { where the reference } \\
\text { ligand can be any } \\
\text { ligand of choice. }\end{array}$ & $\begin{array}{l}\text { A biased ligand for } \\
\text { which the reference } \\
\text { ligand was not selected } \\
\text { based on specific } \\
\text { signaling pathway } \\
\text { qualities has bias only } \\
\text { relative to the reference } \\
\text { ligand, which in itself } \\
\text { can have any bias. }\end{array}$ \\
\hline $\begin{array}{l}\text { Pathway-biased ligand / } \\
\text { signaling }\end{array}$ & $\begin{array}{l}\text { Pathway-balanced ligand } \\
\text { (defined in section } \\
\text { Pathway-biased } \\
\text { ligands/signaling) }\end{array}$ & $\begin{array}{l}\text { Signaling preferentially } \\
\text { via one pathway, as the } \\
\text { reference ligand } \\
\text { approximates a } \\
\text { pathway-balanced signal. }\end{array}$ & $\begin{array}{l}\text { A pathway- } \\
\text { balanced/unbiased ligand } \\
\text { can be physiology-biased, } \\
\text { although it is by } \\
\text { definition unbiased in the } \\
\text { pathway definition. A } \\
\text { balanced ligand in one } \\
\text { system may not be } \\
\text { 'balanced' in another } \\
\text { (applies to all types of } \\
\text { ligand bias). }\end{array}$ \\
\hline $\begin{array}{l}\text { Physiology-biased ligand } \\
\text { / signaling }\end{array}$ & $\begin{array}{l}\text { Principal endogenous } \\
\text { agonist (defined in } \\
\text { section Physiology-biased } \\
\text { ligands/signaling) }\end{array}$ & $\begin{array}{l}\text { Signaling differs from the } \\
\text { natural/canonical, as the } \\
\text { reference ligand } \\
\text { represents the } \\
\text { endogenous response (of } \\
\text { the given receptor and } \\
\text { system). }\end{array}$ & $\begin{array}{l}\text { An endogenous agonist } \\
\text { can be pathway-biased, } \\
\text { although it is by } \\
\text { definition unbiased in the } \\
\text { physiological definition. }\end{array}$ \\
\hline
\end{tabular}

\section{Table 2}

Experimental parameters critical to the unambiguous description of ligand bias. Table entries are examples only.

\begin{tabular}{llll}
\hline & Pathway 1 & Pathway 2 & Pathway 3 \\
\hline $\begin{array}{l}\text { Transducer } \\
\text { ("pathway") }\end{array}$ & B-arrestin 2 & $\mathrm{G}_{\mathrm{i}}$ & $\mathrm{G}_{\mathrm{q}}$ \\
$\begin{array}{l}\text { Cell line } \\
\begin{array}{l}\text { Receptor expression } \\
\text { levels (fmol/mg } \\
\text { protein) }\end{array}\end{array}$ & $\mathrm{CHO}$ & $\mathrm{CHO}$ & $\mathrm{CHO}$ \\
\end{tabular}




\begin{tabular}{|c|c|c|c|}
\hline & Pathway 1 & Pathway 2 & Pathway 3 \\
\hline $\begin{array}{l}\text { Time point }(\mathrm{min}) \text { (For } \\
\text { time-resolved, a span) }\end{array}$ & $15-60$ & 30 & 30 \\
\hline Temperature $\left({ }^{\circ} \mathrm{C}\right)$ & 20 & 20 & 20 \\
\hline $\begin{array}{l}\text { Reference ligand } \\
\text { (endogenous) }\end{array}$ & CP55,940 & $\mathrm{CP} 55,940$ & CP55,940 \\
\hline $\begin{array}{l}\text { Reference ligand for } \\
\text { Emax (if } \\
\text { non-endogenous) }\end{array}$ & - & - & - \\
\hline Measured process & Recruitment & Accumulation & Accumulation \\
\hline $\begin{array}{l}\text { Measured molecule } \\
1 \text { (a GPCR, } \\
\text { transducer, effector } \\
\text { or second } \\
\text { messenger) }\end{array}$ & $\mathrm{CB}_{1}$ & cAMP & $\begin{array}{l}\text { Myo-inositol-1- } \\
\text { phosphate } \\
\text { (IP1) }\end{array}$ \\
\hline $\begin{array}{l}\text { Measured molecule } \\
2 \text { (where applicable) }\end{array}$ & $\beta$-arrestin 2 & & \\
\hline $\begin{array}{l}\text { Signal detection } \\
\text { technique }\end{array}$ & FRET & HTRF & HTRF \\
\hline
\end{tabular}

\section{Table 3}

Ligand bias and underlying data using $\Delta \Delta \log \left(\operatorname{Emax} / \mathrm{EC}_{50}\right)$. Ligand $\mathrm{B}$ has a weak bias (bias factor 0.8) towards pathway 2. This information is retrieved by first calculating a $\Delta \log \left(\operatorname{Emax} / \mathrm{EC}_{50}\right)$ for Ligand $\mathrm{B}-$ Ligand $\mathrm{A}$ (the reference) in each pathway and then a $\Delta \Delta \log \left(\operatorname{Emax} / \mathrm{EC}_{50}\right)$ for Pathway 2 - Pathway 1.

\begin{tabular}{|c|c|c|c|c|c|c|c|}
\hline Ligand & $\Delta \Delta \operatorname{\Lambda o\gamma }(\mathrm{E}$ & $\begin{array}{l}\text { Pathway } 1 \\
\text { ¿ } \alpha \text { Ëfrä: } 00 \% \text { ) }\end{array}$ & $\begin{array}{l}\text { Pathway } 2 \\
\text { Emax (\%) }\end{array}$ & $\begin{array}{l}\text { Pathway } 1 \\
\text { pEC }_{50}\end{array}$ & $\begin{array}{l}\text { Pathway } 2 \\
\text { pEC }_{50}\end{array}$ & $\begin{array}{l}\text { Pathway } 1 \\
\text { CRC slope }\end{array}$ & $\begin{array}{l}\text { Pathway } 2 \\
\text { CRC slope }\end{array}$ \\
\hline Ligand A & $\begin{array}{l}\text { - (reference } \\
\text { ligand, } \\
\text { unbiased by } \\
\text { definition) }\end{array}$ & 100 & 100 & 8.3 & 9.0 & 0.9 & 1.1 \\
\hline Ligand B & 0.8 & 83 & 97 & 8.7 & 10.1 & 1.0 & 1.2 \\
\hline
\end{tabular}

Table 4

Ligand bias and underlying data using $\Delta \Delta \log \left(\tau / \mathrm{K}_{\mathrm{A}}\right)$.

\begin{tabular}{|c|c|c|c|c|c|}
\hline Ligand & $\begin{array}{l}\text { Operational } \\
\text { model } \\
\Delta \Delta \Lambda \text { or }(\tau \\
/ \mathrm{K} \alpha)\end{array}$ & Pathway $1 \tau$ & Pathway $2 \tau$ & Pathway $1 \mathrm{Ka}$ & Pathway $2 \mathrm{Ka}$ \\
\hline 'Ligand A' & $\begin{array}{l}\text { - (reference } \\
\text { ligand, unbiased } \\
\text { by definition) }\end{array}$ & & & & \\
\hline 'Ligand B' & 2.1 & & & & \\
\hline
\end{tabular}

Table 5 
Suggested terms to define the pathway processes at different levels being compared for bias.

\begin{tabular}{ll}
\hline Term & Examples of assay principles \\
\hline Accumulation & $\mathrm{Ca}^{2+}$ or cAMP accumulation \\
Binding/coupling & Proximity \\
Activation & Receptor conformation and G protein activation e.g., GTPase activity, GTPrS binding, or recruitment \\
Dissociation & G protein dissociation/rearrangement \\
Phosphorylation & Incorporation of ${ }^{32} \mathrm{P}$ in a specific protein. Two-dimensional phosphopeptide mapping after orthophosph \\
Recruitment & Subcellular redistribution \\
Signaling & Downstream cellular second messenger levels \\
Internalization & ELISA, Flow cytometry, diffusion-enhanced resonance energy transfer (DERET), enhanced bystander \\
Tissue phenotype & Blood vessel contraction, cell migration, hormone secretion, heart rate, force of contraction, glandular s \\
Transcription & Differential gene arrays after agonism, qPCR, and gene reporter assay. \\
\hline
\end{tabular}

\section{References}

Ahn S, Shenoy SK, Luttrell LM, \& Lefkowitz RJ (2020). SnapShot: beta-Arrestin Functions. Cell 182: 1362-1362 e1361.

Anderson A, Masuho I, Marron Fernandez de Velasco E, Nakano A, Birnbaumer L, Martemyanov KA, et al. (2020). GPCR-dependent biasing of GIRK channel signaling dynamics by RGS6 in mouse sinoatrial nodal cells. Proc Natl Acad Sci U S A 117: 14522-14531.

Armstrong JF, Faccenda E, Harding SD, Pawson AJ, Southan C, Sharman JL, et al. (2020). The IUPHAR/BPS Guide to PHARMACOLOGY in 2020: extending immunopharmacology content and introducing the IUPHAR/MMV Guide to MALARIA PHARMACOLOGY. Nucleic Acids Res 48:D1006-D1021.

Avet C, Mancini A, Breton B, Le Gouill C, Hauser AS, Normand C, et al. (2020). Selectivity Landscape of 100 Therapeutically Relevant GPCR Profiled by an Effector Translocation-Based BRET Platform. bioRxiv: 2020.2004.2020.052027.

Azzi M, Charest PG, Angers S, Rousseau G, Kohout T, Bouvier M, et al. (2003). Beta-arrestin-mediated activation of MAPK by inverse agonists reveals distinct active conformations for G protein-coupled receptors. Proceedings of the National Academy of Sciences of the United States of America 100: 11406-11411.

Baker JG, Hall IP, \& Hill SJ (2003). Agonist and inverse agonist actions of beta-blockers at the human beta 2-adrenoceptor provide evidence for agonist-directed signaling. Molecular pharmacology 64: 1357-1369.

Barlow RB, Scott NC, \& Stephenson RP (1967). The affinity and efficacy of onium salts on the frog rectus abdominis. Br J Pharmacol Chemother 31: 188-196.

Black JW, \& Leff P (1983). Operational models of pharmacological agonism. Proc R Soc Lond B Biol Sci 220: 141-162.

Bockaert J, Fagni L, Dumuis A, \& Marin P (2004). GPCR interacting proteins (GIP). Pharmacology \& therapeutics 103: 203-221.

Bouvier M, Leeb-Lundberg LM, Benovic JL, Caron MG, \& Lefkowitz RJ (1987). Regulation of adrenergic receptor function by phosphorylation. II. Effects of agonist occupancy on phosphorylation of alpha 1- and beta 2-adrenergic receptors by protein kinase $\mathrm{C}$ and the cyclic AMP-dependent protein kinase. The Journal of biological chemistry 262:3106-3113.

Bradley SJ, \& Tobin AB (2016). Design of Next-Generation G Protein-Coupled Receptor Drugs: Linking Novel Pharmacology and In Vivo Animal Models. Annu Rev Pharmacol Toxicol 56: 535-559. 
Carman CV, Parent JL, Day PW, Pronin AN, Sternweis PM, Wedegaertner PB, et al. (1999). Selective regulation of Galpha(q/11) by an RGS domain in the G protein-coupled receptor kinase, GRK2. The Journal of biological chemistry 274: 34483-34492.

Che T, Dwivedi-Agnihotri H, Shukla AK, \& Roth BL (2021). Biased ligands at opioid receptors: Current status and future directions. Science signaling 14.

Chidiac P, Nouet S, \& Bouvier M (1996). Agonist-induced modulation of inverse agonist efficacy at the beta 2-adrenergic receptor. Molecular pharmacology 50: 662-669.

Crilly SE, \& Puthenveedu MA (2021). Compartmentalized GPCR Signaling from Intracellular Membranes. J Membr Biol 254: 259-271.

De Lean A, Stadel JM, \& Lefkowitz RJ (1980). A ternary complex model explains the agonist-specific binding properties of the adenylate cyclase-coupled beta-adrenergic receptor. The Journal of biological chemistry 255: 7108-7117.

Dean T, Vilardaga JP, Potts JT, Jr., \& Gardella TJ (2008). Altered selectivity of parathyroid hormone $(\mathrm{PTH})$ and PTH-related protein (PTHrP) for distinct conformations of the PTH/PTHrP receptor. Mol Endocrinol 22: 156-166.

DebBurman SK, Ptasienski J, Benovic JL, \& Hosey MM (1996). G protein-coupled receptor kinase GRK2 is a phospholipid-dependent enzyme that can be conditionally activated by G protein betagamma subunits. The Journal of biological chemistry 271: 22552-22562.

Dorn GW, 2nd, Oswald KJ, McCluskey TS, Kuhel DG, \& Liggett SB (1997). Alpha 2A-adrenergic receptor stimulated calcium release is transduced by Gi-associated G(beta gamma)-mediated activation of phospholipase C. Biochemistry 36: 6415-6423.

Ehlert FJ (2008). On the analysis of ligand-directed signaling at G protein-coupled receptors. NaunynSchmiedeberg's archives of pharmacology 377: 549-577.

Ehlert FJ, Suga H, \& Griffin MT (2011). Analysis of agonism and inverse agonism in functional assays with constitutive activity: estimation of orthosteric ligand affinity constants for active and inactive receptor states. The Journal of pharmacology and experimental therapeutics 338: 671-686.

Eichel K, Jullie D, Barsi-Rhyne B, Latorraca NR, Masureel M, Sibarita JB, et al. (2018). Catalytic activation of beta-arrestin by GPCRs. Nature 557: 381-386.

Eichel K, Jullie D, \& von Zastrow M (2016). beta-Arrestin drives MAP kinase signalling from clathrin-coated structures after GPCR dissociation. Nat Cell Biol 18: 303-310.

Feinstein TN, Wehbi VL, Ardura JA, Wheeler DS, Ferrandon S, Gardella TJ, et al. (2011). Retromer terminates the generation of cAMP by internalized PTH receptors. Nat Chem Biol 7: 278-284.

Furchott RF (1966). The use of beta-haloaklylamines in the differentiation of the receptors and in the determination of dissociation constants of receptor-agonist complexes. In Adv Drug Res. ed Harper N.J.a.S., A.B. Academic Press, pp 21-55.

Galandrin S, Oligny-Longpre G, \& Bouvier M (2007). The evasive nature of drug efficacy: implications for drug discovery. Trends in pharmacological sciences 28: 423-430.

Ghosh E, Dwivedi H, Baidya M, Srivastava A, Kumari P, Stepniewski T, et al. (2019). Conformational Sensors and Domain Swapping Reveal Structural and Functional Differences between beta-Arrestin Isoforms. Cell Rep 28: 3287-3299 e3286.

Gomes I, Sierra S, Lueptow L, Gupta A, Gouty S, Margolis EB, et al. (2020). Biased signaling by endogenous opioid peptides. Proceedings of the National Academy of Sciences of the United States of America 117: $11820-11828$. 
Grundmann M, Merten N, Malfacini D, Inoue A, Preis P, Simon K, et al. (2018). Lack of beta-arrestin signaling in the absence of active G proteins. Nat Commun 9: 341.

Gurevich EV, Tesmer JJ, Mushegian A, \& Gurevich VV (2012). G protein-coupled receptor kinases: more than just kinases and not only for GPCRs. Pharmacology \& therapeutics 133: 40-69.

Gurevich VV, \& Benovic JL (1997). Mechanism of phosphorylation-recognition by visual arrestin and the transition of arrestin into a high affinity binding state. Molecular pharmacology 51: 161-169.

Gutkind JS, \& Kostenis E (2018). Arrestins as rheostats of GPCR signalling. Nat Rev Mol Cell Biol 19: 615-616.

Hasenhuetl PS, Bhat S, Freissmuth M, \& Sandtner W (2019). Functional Selectivity and Partial Efficacy at the Monoamine Transporters: A Unified Model of Allosteric Modulation and Amphetamine-Induced Substrate Release. Molecular pharmacology 95: 303-312.

Hausdorff WP, Bouvier M, O'Dowd BF, Irons GP, Caron MG, \& Lefkowitz RJ (1989). Phosphorylation sites on two domains of the beta 2-adrenergic receptor are involved in distinct pathways of receptor desensitization. The Journal of biological chemistry 264: 12657-12665.

Hauser AS, Attwood MM, Rask-Andersen M, Schioth HB, \& Gloriam DE (2017). Trends in GPCR drug discovery: new agents, targets and indications. Nat Rev Drug Discov 16: 829-842.

Hay DL, Garelja ML, Poyner DR, \& Walker CS (2018). Update on the pharmacology of calcitonin/CGRP family of peptides: IUPHAR Review 25. Br J Pharmacol 175: 3-17.

Hay DL, \& Pioszak AA (2016). Receptor Activity-Modifying Proteins (RAMPs): New Insights and Roles. Annu Rev Pharmacol Toxicol 56:469-487.

Heidari Z, Chrisman IM, Nemetchek MD, Novick SJ, Blayo AL, Patton T, et al. (2019). Definition of functionally and structurally distinct repressive states in the nuclear receptor PPARgamma. Nat Commun 10: 5825 .

Hillenbrand M, Schori C, Schoppe J, \& Plückthun A (2015). Comprehensive analysis of heterotrimeric G-protein complex diversity and their interactions with GPCRs in solution. Proceedings of the National Academy of Sciences of the United States of America 112: E1181-1190.

Ho MKC, \& Wong YH (2001). Gz signaling: emerging divergence from Gi signaling. Oncogene 20: 1615-1625.

Hoare SRJ, Pierre N, Moya AG, \& Larson B (2018). Kinetic operational models of agonism for G-proteincoupled receptors. J Theor Biol 446: 168-204.

Hollenberg MD, Mihara K, Polley D, Suen JY, Han A, Fairlie DP, et al. (2014). Biased signalling and proteinase-activated receptors (PARs): targeting inflammatory disease. Br J Pharmacol 171:1180-1194.

Hollinger S, \& Hepler JR (2002). Cellular regulation of RGS proteins: modulators and integrators of G protein signaling. Pharmacol Rev 54: 527-559.

Hunton DL, Barnes WG, Kim J, Ren XR, Violin JD, Reiter E, et al.(2005). Beta-arrestin 2-dependent angiotensin II type 1A receptor-mediated pathway of chemotaxis. Molecular pharmacology 67: 1229-1236.

Inoue A, Raimondi F, Kadji FMN, Singh G, Kishi T, Uwamizu A, et al. (2019). Illuminating G-ProteinCoupling Selectivity of GPCRs. Cell 177: 1933-1947 e1925.

Irannejad R, Pessino V, Mika D, Huang B, Wedegaertner PB, Conti M, et al. (2017). Functional selectivity of GPCR-directed drug action through location bias. Nat Chem Biol 13: 799-806.

Jain R, Watson U, Vasudevan L, \& Saini DK (2018). Chapter Three - ERK Activation Pathways Downstream of GPCRs. In Int Rev Cell Mol Biol. ed Shukla A.K. Academic Press, pp 79-109. 
Jensen DD, Lieu T, Halls ML, Veldhuis NA, Imlach WL, Mai QN, et al. (2017). Neurokinin 1 receptor signaling in endosomes mediates sustained nociception and is a viable therapeutic target for prolonged pain relief. Sci Transl Med 9.

Jensen SB, Thodberg S, Parween S, Moses ME, Hansen CC, Thomsen J, et al. (2021). Biased cytochrome P450-mediated metabolism via small-molecule ligands binding P450 oxidoreductase. Nat Commun 12: 2260.

Jiang M, \& Bajpayee NS (2009). Molecular mechanisms of go signaling. Neurosignals 17: 23-41.

Jong YI, Harmon SK, \& O'Malley KL (2019). Location and Cell-Type-Specific Bias of Metabotropic Glutamate Receptor, mGlu5, Negative Allosteric Modulators. ACS Chem Neurosci 10:4558-4570.

Karl K, Paul MD, Pasquale EB, \& Hristova K (2020). Ligand bias in receptor tyrosine kinase signaling. The Journal of biological chemistry 295: 18494-18507.

Kenakin T (1995). Agonist-receptor efficacy. II. Agonist trafficking of receptor signals. Trends in pharmacological sciences 16:232-238.

Kenakin T (1997). Differences between natural and recombinant G protein-coupled receptor systems with varying receptor/G protein stoichiometry. Trends in pharmacological sciences 18: 456-464.

Kenakin T (2015). The Effective Application of Biased Signaling to New Drug Discovery. Molecular pharmacology 88: 1055-1061.

Kenakin T (2019). Biased Receptor Signaling in Drug Discovery. Pharmacol Rev 71: 267-315.

Kenakin T (2021). Biased signaling as allosteric probe dependence. Cell Signal 79: 109844.

Kenakin TP, \& Morgan PH (1989). Theoretical effects of single and multiple transducer receptor coupling proteins on estimates of the relative potency of agonists. Molecular pharmacology 35:214-222.

Klein Herenbrink C, Sykes DA, Donthamsetti P, Canals M, Coudrat T, Shonberg J, et al. (2016). The role of kinetic context in apparent biased agonism at GPCRs. Nat Commun 7: 10842.

Kohout TA, Nicholas SL, Perry SJ, Reinhart G, Junger S, \& Struthers RS (2004). Differential desensitization, receptor phosphorylation, beta-arrestin recruitment, and ERK1/2 activation by the two endogenous ligands for the CC chemokine receptor 7. The Journal of biological chemistry 279: 23214-23222.

Komolov KE, \& Benovic JL (2018). G protein-coupled receptor kinases: Past, present and future. Cell Signal 41: $17-24$.

Lane JR, May LT, Parton RG, Sexton PM, \& Christopoulos A (2017). A kinetic view of GPCR allostery and biased agonism. Nat Chem Biol 13: 929-937.

Lefkowitz RJ, Mullikin D, \& Caron MG (1976). Regulation of beta-adrenergic receptors by guanyl-5'-yl imidodiphosphate and other purine nucleotides. The Journal of biological chemistry 251:4686-4692.

Luttrell LM, Maudsley S, \& Gesty-Palmer D (2018). Translating in vitro ligand bias into in vivo efficacy. Cell Signal 41: 46-55.

Luttrell LM, Roudabush FL, Choy EW, Miller WE, Field ME, Pierce KL, et al. (2001). Activation and targeting of extracellular signal-regulated kinases by beta-arrestin scaffolds. Proc Natl Acad Sci U S A 98: 2449-2454.

Maguire ME, Van Arsdale PM, \& Gliman AG (1976). An Agonist-Specific Effect of Guanine Nucleotides on Binding to the $<\mathrm{em}>$ Beta $</$ em $>$ Adrenergic Receptor. Mol Pharmacol 12: 335-339.

Masuho I, Skamangas NK, Muntean BS, \& Martemyanov KA (2021). Diversity of the Gbetagamma complexes defines spatial and temporal bias of GPCR signaling. Cell Syst 12: 324-337 e325. 
Maurice P, Guillaume JL, Benleulmi-Chaachoua A, Daulat AM, Kamal M, \& Jockers R (2011). GPCRinteracting proteins, major players of GPCR function. Adv Pharmacol 62: 349-380.

Milligan G, \& Kostenis E (2006). Heterotrimeric G-proteins: a short history. Br J Pharmacol 147 Suppl 1: S46-55.

Neubig RR, \& Siderovski DP (2002). Regulators of G-protein signalling as new central nervous system drug targets. Nat Rev Drug Discov 1: 187-197.

Oliver EE, Hughes EK, Puckett MK, Chen R, Lowther WT, \& Howlett AC (2020). Cannabinoid Receptor Interacting Protein 1a (CRIP1a) in Health and Disease. Biomolecules 10.

Olsen RHJ, DiBerto JF, English JG, Glaudin AM, Krumm BE, Slocum ST, et al. (2020). TRUPATH, an open-source biosensor platform for interrogating the GPCR transducerome. Nat Chem Biol 16:841-849.

Onaran HO, Ambrosio C, Ugur O, Madaras Koncz E, Gro MC, Vezzi V, et al. (2017). Systematic errors in detecting biased agonism: Analysis of current methods and development of a new model-free approach. Scientific reports 7: 44247 .

Onaran HO, \& Costa T (2021). Conceptual and experimental issues in biased agonism. Cell Signal 82: 109955.

Ostermaier MK, Schertler GF, \& Standfuss J (2014). Molecular mechanism of phosphorylation-dependent arrestin activation. Current opinion in structural biology 29: 143-151.

Rajagopal S, Ahn S, Rominger DH, Gowen-MacDonald W, Lam CM, Dewire SM, et al. (2011). Quantifying ligand bias at seven-transmembrane receptors. Molecular pharmacology 80: 367-377.

Rajagopal S, Kim J, Ahn S, Craig S, Lam CM, Gerard NP, et al.(2010). Beta-arrestin- but not G proteinmediated signaling by the "decoy" receptor CXCR7. Proc Natl Acad Sci U S A 107: 628-632.

Ribas C, Penela P, Murga C, Salcedo A, Garcia-Hoz C, Jurado-Pueyo M, et al. (2007). The G protein-coupled receptor kinase (GRK) interactome: role of GRKs in GPCR regulation and signaling. Biochim Biophys Acta 1768: 913-922.

Roth BL, \& Chuang DM (1987). Multiple mechanisms of serotonergic signal transduction. Life Sci 41: 10511064 .

Sauliere A, Bellot M, Paris H, Denis C, Finana F, Hansen JT, et al. (2012). Deciphering biased-agonism complexity reveals a new active AT1 receptor entity. Nat Chem Biol 8: 622-630.

Schmid CL, Raehal KM, \& Bohn LM (2008). Agonist-directed signaling of the serotonin 2A receptor depends on beta-arrestin-2 interactions in vivo. Proceedings of the National Academy of Sciences of the United States of America 105: 1079-1084.

Shubhi Pandey PK, Mithu Baidya, Ryoji Kise, Yubo Cao, Hemlata Dwivedi-Agnihotri, Ramanuj Banerjee, Xaria X. Li, Cedric S. Cui, John D. Lee, Kouki Kawakami, Madhu Chaturvedi, Ashutosh Ranjan, Stéphane A. Laporte, Trent M. Woodruff, Asuka Inoue, Arun K. Shukla (2021). Intrinsic bias at non-canonical, $\beta$ arrestin-coupled seven transmembrane receptors. bioRxiv.

Slosky LM, Caron MG, \& Barak LS (2021). Biased Allosteric Modulators: New Frontiers in GPCR Drug Discovery. Trends in pharmacological sciences 42: 283-299.

Smith JS, Lefkowitz RJ, \& Rajagopal S (2018). Biased signalling: from simple switches to allosteric microprocessors. Nat Rev Drug Discov 17: 243-260.

Smith JS, Pack TF, Inoue A, Lee C, Zheng K, Choi I, et al.(2021). Noncanonical scaffolding of Galphai and beta-arrestin by $\mathrm{G}$ protein-coupled receptors. Science 371 . 
Sommer ME, Selent J, Carlsson J, De Graaf C, Gloriam DE, Keseru GM, et al. (2020). The European Research Network on Signal Transduction (ERNEST): Toward a Multidimensional Holistic Understanding of G Protein-Coupled Receptor Signaling. ACS Pharmacol Transl Sci 3: 361-370.

Spengler D, Waeber C, Pantaloni C, Holsboer F, Bockaert J, Seeburg PH, et al. (1993). Differential signal transduction by five splice variants of the PACAP receptor. Nature 365: 170-175.

Sriram K, \& Insel PA (2018). G Protein-Coupled Receptors as Targets for Approved Drugs: How Many Targets and How Many Drugs? Molecular pharmacology 93: 251-258.

Srivastava A, Gupta B, Gupta C, \& Shukla AK (2015). Emerging Functional Divergence of beta-Arrestin Isoforms in GPCR Function. Trends Endocrinol Metab 26: 628-642.

Stahl EL, Ehlert FJ, \& Bohn LM (2019). Quantitating Ligand Bias Using the Competitive Model of Ligand Activity. Methods Mol Biol 1957: 235-247.

Stahl EL, Zhou L, Ehlert FJ, \& Bohn LM (2015). A novel method for analyzing extremely biased agonism at $\mathrm{G}$ protein-coupled receptors. Molecular pharmacology 87: 866-877.

Stallaert W, Christopoulos A, \& Bouvier M (2011). Ligand functional selectivity and quantitative pharmacology at G protein-coupled receptors. Expert Opin Drug Discov 6: 811-825.

Stephenson RP (1956). A modification of receptor theory. Br J Pharmacol Chemother 11: 379-393.

Strachan RT, Sciaky N, Cronan MR, Kroeze WK, \& Roth BL (2010). Genetic deletion of p90 ribosomal S6 kinase 2 alters patterns of 5-hydroxytryptamine 2A serotonin receptor functional selectivity. Molecular pharmacology 77: 327-338.

Thomsen ARB, Plouffe B, Cahill TJ, 3rd, Shukla AK, Tarrasch JT, Dosey AM, et al. (2016). GPCR-G Protein-beta-Arrestin Super-Complex Mediates Sustained G Protein Signaling. Cell 166: 907-919.

Tobin AB, Totty NF, Sterlin AE, \& Nahorski SR (1997). Stimulus-dependent phosphorylation of G-proteincoupled receptors by casein kinase 1alpha. The Journal of biological chemistry 272:20844-20849.

Tsvetanova NG, \& von Zastrow M (2014). Spatial encoding of cyclic AMP signaling specificity by GPCR endocytosis. Nat Chem Biol 10:1061-1065.

Urban JD, Clarke WP, von Zastrow M, Nichols DE, Kobilka B, Weinstein H, et al. (2007). Functional selectivity and classical concepts of quantitative pharmacology. The Journal of pharmacology and experimental therapeutics 320: 1-13.

Wacker D, Stevens RC, \& Roth BL (2017). How Ligands Illuminate GPCR Molecular Pharmacology. Cell 170: $414-427$.

Wehbi VL, Stevenson HP, Feinstein TN, Calero G, Romero G, \& Vilardaga JP (2013). Noncanonical GPCR signaling arising from a PTH receptor-arrestin-Gbetagamma complex. Proceedings of the National Academy of Sciences of the United States of America 110:1530-1535.

Whalen EJ, Rajagopal S, \& Lefkowitz RJ (2011). Therapeutic potential of beta-arrestin- and G proteinbiased agonists. Trends in molecular medicine 17: 126-139.

White KL, Scopton AP, Rives ML, Bikbulatov RV, Polepally PR, Brown PJ, et al. (2014). Identification of novel functionally selective kappa-opioid receptor scaffolds. Molecular pharmacology 85:83-90. 